\title{
A descriptive analysis of the effect of the national COVID-19 lockdown on the workload and case mix of patients presenting to a district-level emergency centre in Cape Town, South Africa
}

\author{
C Hendrikse, ${ }^{1,2}$ MB ChB, MMed (Emergency Medicine), FCEM (SA); M Parak, ${ }^{2}$ MBBS; \\ D J van Hoving, ${ }^{3}$ MB ChB, MMed (Emergency Medicine), Dip PEC (SA), MScMedSci (Clinical Epidemiology) \\ ${ }^{1}$ Division of Emergency Medicine, Faculty of Health Sciences, University of Cape Town, South Africa \\ ${ }^{2}$ Emergency centres, Mitchells Plain and Heideveld hospitals, Cape Town, South Africa \\ ${ }^{3}$ Division of Emergency Medicine, Faculty of Medicine and Health Sciences, Stellenbosch University, Cape Town, South Africa
}

Corresponding author: C Hendrikse (clint.hendrikse@uct.ac.za)

\begin{abstract}
Background. The global COVID-19 pandemic caused many countries to institute nationwide lockdowns to limit the spread of the disease. Objectives. To describe the effect of the national COVID-19 lockdown in South Africa (SA) on the workload and case mix of patients presenting to a district-level emergency centre.

Methods. The electronic patient tracking and registration database at Mitchells Plain Hospital, a district-level hospital in Cape Town, was retrospectively analysed. The 5 -week lockdown period (27 March - 30 April 2020) was compared with a similar period immediately before the lockdown (21 February - 26 March). A comparison was also made with corresponding time periods during 2018 and 2019. Patient demographics, characteristics, diagnoses and disposition, as well as process times, were compared.

Results. A total of 26164 emergency centre visits were analysed (8 297 in 2020, 9726 in 2019, 8141 in 2018). There was a reduction of $15 \%$ in overall emergency centre visits from 2019 to 2020 (non-trauma 14\%, trauma 20\%). A 35\% decrease was seen between the 2020 lockdown period and the 5-week period before lockdown (non-trauma 33\%, trauma $43 \%$ ), and the reduced number of visits stayed similar throughout the lockdown period. The median age increased by 5 years during the 2020 lockdown period, along with an $8 \%$ decrease in patients aged $<12$ years. High-acuity patients increased by $6 \%$ and the emergency centre mortality rate increased by $1 \%$. All process times were shorter during the lockdown period (time to triage $-24 \%$, time to consultation $-56 \%$, time to disposition decision $-29 \%$, time in the emergency centre $-20 \%$ ).

Conclusions. The SA national COVID-19 lockdown resulted in a substantial decrease in the number of patients presenting to the emergency centre. It is yet to be seen how quickly emergency centre volumes will recover as lockdown measures are eased.

S Afr Med J 2020;110(11):1113-1118. https://doi.org/10.7196/SAMJ.2020.v110i11.15028
\end{abstract}

The COVID-19 pandemic, caused by SARS-CoV-2, has changed the way of life across the world. The most pertinent measure that was implemented was social distancing, with the intention to reduce transmission and to lessen the acute burden imposed on the healthcare system. Social distancing refers to the practice of increasing and maintaining the physical space between people in order to decrease the chance of spreading contagious diseases. $^{[1]}$ Individual actions further include wearing a cloth face covering, avoiding large public gatherings, limiting use of public transportation, and working from home if possible. ${ }^{[2]}$ Many countries across the globe instituted national lockdown measures to minimise contact with potentially infected persons, and it is estimated that more than a third of the global population were simultaneously under some sort of lockdown at the height of the outbreak in May 2020. ${ }^{[3]}$

Healthcare facilities have braced themselves for the expected wave of COVID-19 patients, but the potential impact on acute care services remains uncertain, as other diseases will continue to present during the pandemic. Previous outbreaks have demonstrated that when health systems are overwhelmed, mortality from other treatable conditions can also increase dramatically. During the
2014 - 2015 Ebola outbreak, the number of deaths caused by measles, malaria, HIV/AIDS and tuberculosis far exceeded deaths from Ebola, ${ }^{[4]}$ the main reason being the reduction in access to healthcare services.

Emergency centres are the frontline medical response during an outbreak of a pandemic disease and can quickly be stretched to their limits. Emergency centres in the USA experienced an 18\% increase in overall visits during the 2009 influenza A(H1N1)pdm09 pandemic. ${ }^{[5]}$ On the other hand, emergency centres often recorded a substantial reduction in patient volumes during the peak of an epidemic. Emergency centre visits decreased by a third during the 2015 MERS (Middle East respiratory syndrome) outbreak in Korea, ${ }^{[6]}$ and halved in Taiwan at the peak of the 2003 SARS (severe acute respiratory syndrome) epidemic. ${ }^{[7]}$ There have also been anecdotal reports of decreased patient volumes during the current COVID-19 pandemic. $^{[8,9]}$

The first detected case of COVID-19 in South Africa (SA) was diagnosed on 5 March 2020, and a National State of Disaster was declared on 23 March. ${ }^{[10]}$ This included the institution of a 21-day nation-wide lockdown which was extended by a further 2 weeks (27 March - 30 April). ${ }^{[1]}$ SA's lockdown was deemed one of the 
strictest around the world and was mainly instituted to buy some time for the overburdened public hospital system to increase its capacity in anticipation of the influx of COVID-19 patients. ${ }^{[12]}$ Primary level healthcare services in SA are provided by local clinics and 24-hour community health centres, and the country has a three-tiered hospital system consisting of district (level 1), regional (level 2) and tertiary/central (level 3) hospitals. ${ }^{[13]}$ District-level hospitals are equipped to provide basic diagnostic and therapeutic services, and specialist services are not always available. ${ }^{[13]}$ Data on the impact of the COVID-19 pandemic and the associated social distancing measures on entry-level healthcare facilities are lacking.

\section{Objectives}

To describe the effect of the COVID-19 lockdown on the workload and case mix of patients presenting to a district-level emergency centre in Cape Town, SA.

\section{Methods \\ Study design}

A retrospective analysis of a prospectively collected observational database was conducted.

\section{Study setting}

Mitchells Plain Hospital is a 230-bed district-level hospital, situated $\sim 32 \mathrm{~km}$ from Cape Town's city centre. It serves a population of $\sim 600000$, which includes the population of Mitchells Plain and the greater part of Philippi, a large nearby township. Looking at demographics, Mitchells Plain is home to low- to middle-income families, of which $90 \%$ are coloured; ${ }^{[14]}$ Philippi has a low-income community that comprises $90 \%$ black residents. ${ }^{[15]}$ The area battles with social challenges, including gangsterism, crime, drug abuse, unemployment and poverty. Interpersonal violence and other injuries are particularly prevalent over weekends. ${ }^{[16]}$ The emergency centre manages $\sim 50000$ patients annually, with $\sim 60 \%$ being of high acuity.

Mitchells Plain Hospital utilises an electronic patient tracking and registration database called HECTIS (Hospital and Emergency Centre Tracking Information System). It was primarily designed for administrative and management purposes in order to streamline and track patient processes in the emergency centre, including their process times, triage scores, diagnoses and dispositions. Routine clinical data are collected for every patient who enters the emergency centre. The data are stored electronically on an off-site Oracle database, version 12.1.0.2.0 (Oracle Corp., USA) and are automatically backed up daily. Authorised users can access the data via the HECTIS application using an active-directory authenticated login and password. Users of the registry are granted access and authorisation according to their clinical role, e.g. a clinician will access a different part of HECTIS to a triage nurse.

\section{Study participants}

Convenience sampling was used to include all patients who presented to the emergency centre at Mitchells Plain Hospital over the study periods, which were the 5-week lockdown period (27 March - 30 April 2020), a 5-week period immediately before the lockdown (21 February - 26 March), and corresponding periods during 2019 and 2018.

\section{Data collection and management}

Data were exported from the HECTIS database for the various study periods. Variables included age, gender, mode of transport, type of presentation, patient acuity, diagnoses, process times and disposition. The South African Triage Scale (SATS) was used to determine patient acuity, and categorises patients as non-urgent (green), urgent (yellow), very urgent (orange) and emergency (red). ${ }^{[17]}$ Patient acuity was determined at arrival to the hospital. Patient comorbidities and diagnoses were determined from completed International Statistical Classification of Diseases and Related Health Problems, 10th revision (ICD-10) codes. Electronic timestamps were used to calculate process times and included time to triage (hospital arrival to time of triage), time to consultation (hospital arrival to time seen by physician), time to disposition decision (hospital arrival to decision time of emergency centre disposition), and time in the emergency centre (hospital arrival till emergency centre exit time). The emergency centre arrival time was used when patients did not initially present directly to the emergency centre (e.g. referred via the outpatient department).

\section{Statistical analysis}

Summary statistics were used to describe all variables. Categorical data were summarised using frequency counts and percentages, and distributions of variables are presented as two-way tables or bar charts. Continuous variables (age and process times) are presented as medians with quartiles. Process times of patients who absconded were only included to calculate the time to triage (if a triage time was documented) and were excluded from the rest. Data were analysed using SPSS Statistics for Windows, version 26.0 (IBM Corp., USA).

\section{Patient and public involvement statement}

This research was done without patient involvement. Patients were not invited to comment on the study design and were not consulted to develop patient-relevant outcomes or interpret the results. Patients were not invited to contribute to the writing or editing of this article for readability or accuracy.

\section{Ethics approval}

The study was approved by the Health Research Ethics Committee of Stellenbosch University (ref. no. N20/04/009_COVID-19), and approval included a waiver of informed consent.

\section{Results}

A total of 26164 emergency centre visits were analysed after 264 cases (1\%) were excluded (visit only relating to special investigations $n=175$, direct referral to inpatient disciplines $n=89$ ). There were 8297 emergency centre visits recorded during the 2020 time periods, 9726 during 2019 and 8141 during 2018. A decrease in emergency centre visits occurred during the 2020 lockdown period compared with the corresponding periods in 2018 and 2019 (Fig. 1).

Emergency centre visits decreased by $15 \%(n=1429)$ from 2019 to 2020 (non-trauma $n=1080 ; 14 \%$, trauma $n=349 ; 20.1 \%$ ), but by $35 \%$ ( $n=1738)$ over the lockdown periods (non-trauma $n=1638 ; 33 \%$, trauma $n=370 ; 43 \%$ ), despite an increase from 2018 to 2019 (Table 1). The lockdown period in 2020 resulted in a $35 \%$ ( $n=1731$ ) reduction in emergency centre visits compared with the pre-lockdown period (Table 1$)$, with a $45 \%(n=408)$ reduction in trauma cases and a $32 \%(n=1323)$ reduction in non-trauma cases. The decrease in the number of emergency centre visits was seen over the entire lockdown period (Fig. 2), including the notoriously busy Easter weekend (Fig. 3).

Demographics and characteristics of patients are presented in Table 2. The median age increased by 5 years during the 2020 
lockdown period compared with the 2020 pre-lockdown period, with an $8 \%$ decrease in paediatric presentations. Fewer patients presented via a general practitioner (3\% decrease), but more used ambulances as transport method ( $4 \%$ increase). There was a $6 \%$ increase in high-acuity patients (triaged orange or red) compared with the 2020 pre-lockdown period. This increase in patient acuity is also reflected in the proportional increases in referrals to inpatient disciplines ( $8 \%$ increase) and in patients who died while in the emergency centre (1\% increase) (Table 2, Fig. 4).

\section{Discussion}

The national COVID-19 lockdown measures resulted in a decreased workload at a districtlevel emergency centre. A $14 \%$ decrease in emergency centre visits occurred during the 2020 lockdown period compared with the corresponding period in 2019. A 35\% reduction was also seen compared with the 5-week period before the national lockdown was instituted, and this decrease remained constant until the end of the lockdown period. The time to consultation decreased by $56 \%$, even with more patients presenting with high-acuity disease.

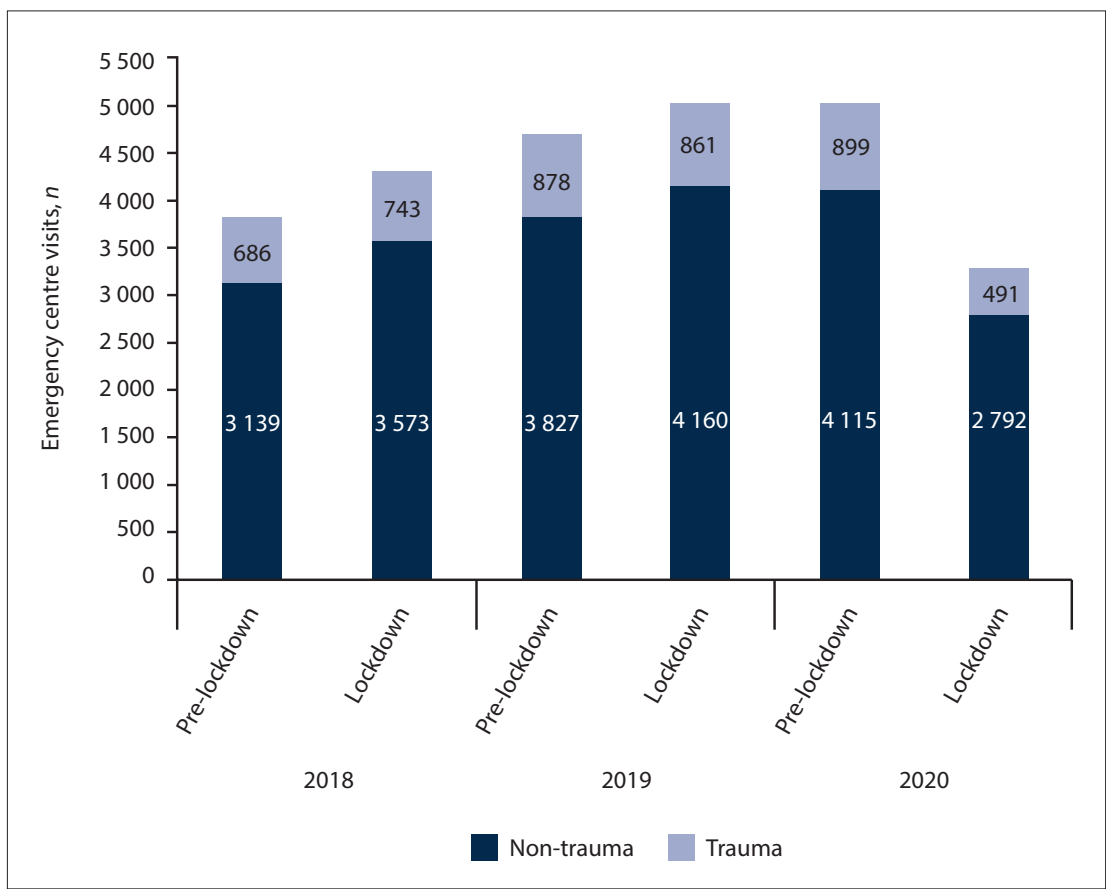

Fig. 1. Number of emergency centre visits over 3 consecutive years representing the 5-week periods directly before and during the 2020 COVID-19 lockdown and similar periods during the 2 preceding years (pre-lockdown (or corresponding) period 21 February - 26 March; lockdown (or corresponding) period 27 March - 30 April).

The substantial decrease in the number of emergency visits during the COVID19 lockdown period is similar to previous epidemics. A significant reduction in patients presenting to emergency centres was also experienced during the 2003 SARS epidemic. A $52 \%$ reduction in daily emergency centre visits occurred in Taiwan, ${ }^{[7]}$ with noticeable reductions in respiratory diseases (e.g. acute bronchitis, upper respiratory infection) and minor ailments (e.g. gastrointestinal disorders and back pain). ${ }^{[18]}$ A Hong Kong emergency centre also documented a $24 \%$ reduction in overall emergency centre visits and a 39\% reduction in trauma-related visits. ${ }^{[19]}$ This reduction in emergency centre visits also occurred during the 2015 MERS epidemic, where the emergency centre attendance of a Korean emergency centre decreased by $33 \% .{ }^{[6]}$

The reduction in emergency centre visits seems contradictory during an epidemic or pandemic. One would expect an increase in patients, especially related to the epidemic itself. The de-escalation of outpatient services and elective surgery during the lockdown period was also projected to increase the number of emergency centre visits, as these patients were expected to seek medical care from the emergency centres. An increase in process times was further expected if the inpatient disciplines are overwhelmed, resulting in an overflow into the emergency centre. The reduction in emergency centre visits seems to be caused by two main factors. Firstly, people are afraid to visit healthcare facilities, staying away in order to avoid contracting the disease. ${ }^{[19,20]} \mathrm{A}$ recent US survey indicated that $29 \%$ of adults had delayed or avoided medical care because they were concerned about contracting COVID-19. ${ }^{[21]}$ Secondly,

Table 1. Differences in the number of emergency centre presentations for the 5-week COVID-19 lockdown and pre-lockdown periods $s^{\star}$ and corresponding periods for 2 years prior to the lockdown

\begin{tabular}{|c|c|c|c|c|c|c|}
\hline & \multicolumn{3}{|c|}{ Difference between years, $n(\%)$} & \multicolumn{3}{|c|}{$\begin{array}{l}\text { Difference between } 5 \text {-week periods } \\
\text { (lockdown v. pre-lockdown), } n(\%)\end{array}$} \\
\hline & 2019 v. 2018 & 2020 v. 2019 & 2020 v. 2018 & 2018 & 2019 & 2020 \\
\hline All & $1585(20)$ & $-1429(-15)$ & $156(2)$ & $491(13)$ & $316(7)$ & $-1731(-35)$ \\
\hline Pre-lockdown & $880(23)$ & $309(7)$ & $1189(31)$ & - & - & - \\
\hline Lockdown & $705(16)$ & $-1738(-35)$ & $-1033(-24)$ & - & - & - \\
\hline Non-trauma & $1275(19)$ & $-1080(-14)$ & $195(3)$ & $434(14)$ & $333(9)$ & $-1323(-32)$ \\
\hline Pre-lockdown & $688(22)$ & $288(8)$ & $976(31)$ & - & - & - \\
\hline Lockdown & $587(16)$ & $-1368(-33)$ & $-781(-22)$ & - & - & - \\
\hline Trauma & $310(22)$ & $-349(-20)$ & $-39(-3)$ & $57(8)$ & $-17(-2)$ & $-408(-46)$ \\
\hline Pre-lockdown & $192(28)$ & $21(2)$ & $213(31)$ & - & - & - \\
\hline Lockdown & $118(16)$ & $-370(-43)$ & $-252(-34)$ & - & - & - \\
\hline
\end{tabular}




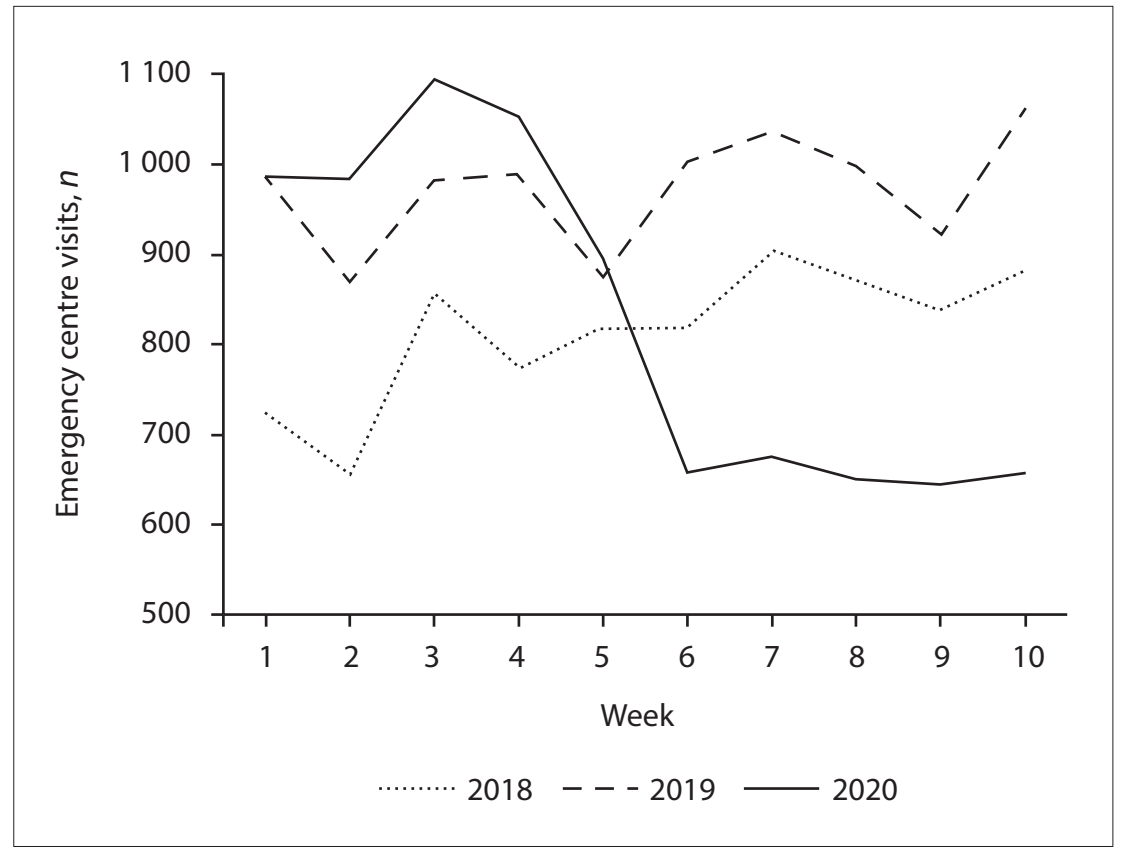

Fig. 2. Number of emergency visits per week during the 5-week national COVID-19 lockdown period (weeks 6 - 10) and the corresponding time period immediately before the lockdown period (weeks 1 - 5).

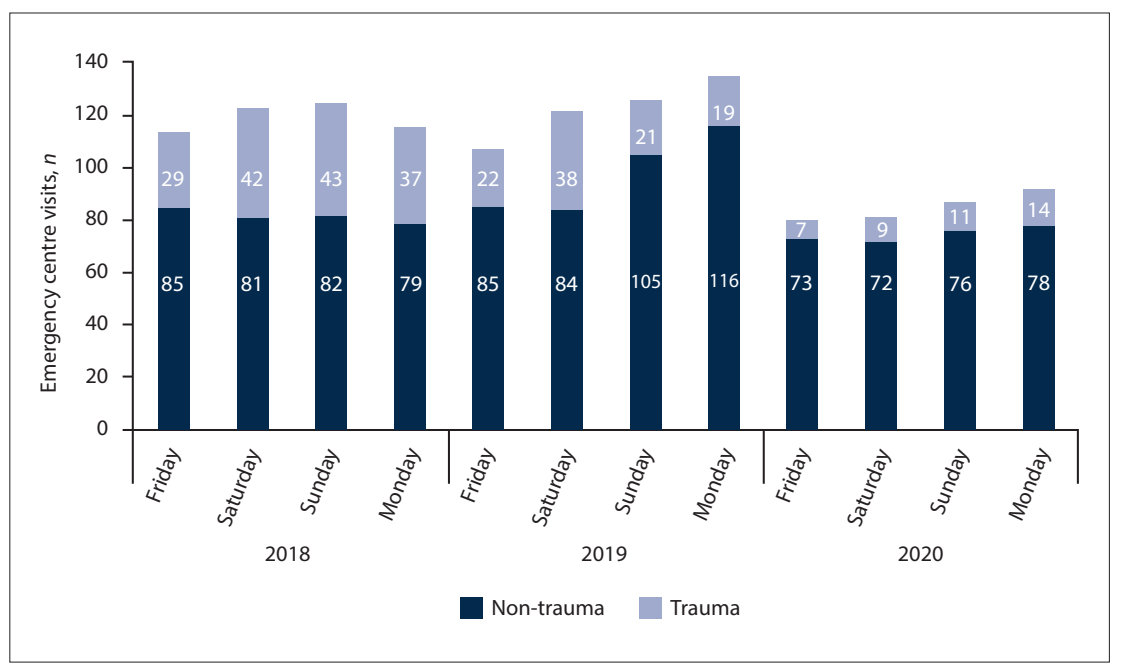

Fig. 3. Number of emergency centre visits over the Easter weekend for 3 consecutive years (Easter 2020 fell within the national COVID-19 lockdown period).

the changes in community behaviour (either spontaneous, or enforced as during COVID19 lockdowns) during an epidemic result in a lower incidence of trauma and other diseases. ${ }^{[19]}$ The decrease in traffic volumes could result in fewer trauma presentations, ${ }^{[2]}$ whereas patients with minor illnesses may decide to self-medicate at home. An additional factor in our study was that the national lockdown in SA was implemented at a very early stage of the pandemic: only a total of 1170 cases and 1 death had been confirmed on the day the lockdown period started. ${ }^{[23]}$ More patients may have presented to the emergency centre if the lockdown the overall number of patients (mainly the less acute patients) decreased. However, the absolute number increased compared with 2019 and with the period immediately before the 2020 lockdown. Existing evidence indicates that delayed onset of emergency care increases patient mortality, ${ }^{[25]}$ and it is a possible reason for the increase in the mortality rate. The delay in seeking medical care could even be more detrimental in terms of mortality, as patients may die before reaching the emergency centre. Anecdotal evidence from areas in the USA indicates a five-fold increase in deaths at home. ${ }^{[9]}$

\section{Study limitations}

This study has limitations. It was a retrospective analysis using an existing electronic database from a single district-level facility. The results do not reflect the workload and characteristics of patients presenting to other healthcare facilities, and care must be taken in generalising the results. Diagnostic codes (ICD-10) were also used as a surrogate measure of disease and may not be entirely accurate. We did not attempt to quantify any potential misclassifications and subsequent bias that could have resulted from either the validity of the diagnosis made or the association between the diagnostic code and the documented diagnosis. Nonetheless, we are confident that the results are closely related to the truth.

\section{Key messages}

What is already known on this topic

- Many healthcare systems have been overburdened during the COVID-19 pandemic

- Reports from previous epidemics (e.g. SARS, MERS) indicated a decrease in emergency centre volumes at the peak of the epidemic

- The effect of lockdown on the workload of district-level emergency centres is not known.

period had coincided with a later stage of the pandemic.

People's fear of attending healthcare facilities during an epidemic has a downside. Delay in seeking or avoidance of medical care results in patients being sicker when they do present to the emergency centre. This was evident in the $6 \%$ increase in high-acuity patients, and corresponds to the report from an emergency centre in Canada that presenting patients were sicker than is usually seen. ${ }^{[24]}$ A $1 \%$ increase in the emergency centre mortality rate was also documented in our study. One could argue that the percentage is inflated, since
What this study adds

- Our study indicates a decrease in patient volumes at a district-level emergency centre during the COVID-19 lockdown period

- Patients who did visit the emergency centre had a higher acuity of disease, and a higher proportion were admitted to inpatient disciplines.

\section{Conclusions}

The SA national COVID-19 lockdown resulted in a substantial decrease in the 


\begin{tabular}{|c|c|c|c|c|c|c|}
\hline & \multicolumn{2}{|c|}{2018} & \multicolumn{2}{|c|}{2019} & \multicolumn{2}{|c|}{2020} \\
\hline & $\begin{array}{l}\text { Pre-lockdown } \\
(N=3825)\end{array}$ & $\begin{array}{l}\text { Lockdown } \\
(N=4316) \\
\end{array}$ & $\begin{array}{l}\text { Pre-lockdown } \\
(N=4 \text { 705) }\end{array}$ & $\begin{array}{l}\text { Lockdown } \\
(N=5021)\end{array}$ & $\begin{array}{l}\text { Pre-lockdown } \\
(N=5 \text { 014) }\end{array}$ & $\begin{array}{l}\text { Lockdown } \\
(N=3283)\end{array}$ \\
\hline \multicolumn{7}{|l|}{ Age (years) } \\
\hline Median (Q1 - Q3) & $29(11-45)$ & $28(8-44)$ & $29(9-46)$ & $29(9-46)$ & $29(10-47)$ & $34(21-53)$ \\
\hline$\leq 12$ years, $n(\%)$ & $963(25)$ & $1166(27)$ & $1242(26)$ & $1380(28)$ & $1299(26)$ & $581(18)$ \\
\hline \multicolumn{7}{|l|}{ Gender, $n(\%)$} \\
\hline Male & $1913(50)$ & $2171(50)$ & $2427(52)$ & $2540(51)$ & $2578(51)$ & $1664(51)$ \\
\hline Female & $1912(50)$ & $2145(50)$ & $2278(48)$ & $2481(49)$ & $2436(49)$ & $1619(49)$ \\
\hline \multicolumn{7}{|l|}{ Arrived from, $n$ (\%) } \\
\hline Scene/home & $2425(64)$ & $2865(66)$ & $3210(68)$ & $3515(70)$ & $3453(69)$ & $2376(72)$ \\
\hline Other healthcare facility & $910(23.8)$ & $895(21)$ & 913 (19) & $850(17)$ & 959 (19) & $599(18)$ \\
\hline General practitioner & $489(12.8)$ & $556(13)$ & $574(12)$ & $637(13)$ & $587(12)$ & $301(9)$ \\
\hline Unknown & $1(<1)$ & 0 & $8(<1)$ & $19(<1)$ & $15(<1)$ & $7(<1)$ \\
\hline \multicolumn{7}{|l|}{ Transport method, $n$ (\%) } \\
\hline Self & $2512(66)$ & $2915(68)$ & $2900(62)$ & $3169(63)$ & $3108(62)$ & $1987(61)$ \\
\hline Ambulance & $753(20)$ & $772(18)$ & $1109(24)$ & $1084(22)$ & $1169(23)$ & $896(27)$ \\
\hline Fire or police services & $24(<1)$ & $26(<1)$ & $56(1)$ & $53(1)$ & $46(1)$ & $20(1)$ \\
\hline Unknown & $536(14)$ & $603(14)$ & $640(14)$ & $715(14)$ & $691(14)$ & $380(12)$ \\
\hline \multicolumn{7}{|l|}{ Patient acuity, $n(\%)^{\dagger}$} \\
\hline Non-urgent (green) & $319(8)$ & $284(7)$ & $377(8)$ & $393(8)$ & $427(9)$ & $259(8)$ \\
\hline Urgent (yellow) & $1990(52)$ & $2178(51)$ & $2232(47)$ & $2323(46)$ & $2249(45)$ & $1295(39)$ \\
\hline Very urgent (orange) & $1259(33)$ & $1562(36)$ & $1814(39)$ & $1889(38)$ & $1992(40)$ & $1485(45)$ \\
\hline Emergency (red) & $149(4 \%$ & $168(4)$ & $175(4)$ & $226(5)$ & $200(4)$ & $171(5)$ \\
\hline Unknown & $108(3)$ & $124(3)$ & $107(2)$ & $190(4)$ & $146(3)$ & $73(2)$ \\
\hline \multicolumn{7}{|l|}{ Diagnostic category, $n(\%)$} \\
\hline Medical & $1982(52)$ & $2289(53)$ & $2470(53)$ & $2561(53)$ & $2540(51)$ & $1798(55)$ \\
\hline Trauma & $686(18)$ & $743(17)$ & 878 (19) & $861(17)$ & $899(18)$ & $491(15)$ \\
\hline Surgical & $472(12)$ & $484(11)$ & $420(9)$ & $438(9)$ & $496(10)$ & $356(11)$ \\
\hline Obstetrics and gynaecology & $194(5)$ & $206(5)$ & $216(5)$ & $225(5)$ & $218(4)$ & $203(6)$ \\
\hline Psychiatry & $149(4)$ & $149(4)$ & $160(3)$ & $174(4)$ & $207(4)$ & $144(4)$ \\
\hline Toxicology & $53(1)$ & $54(1)$ & $58(1)$ & $55(1)$ & $62(1)$ & $37(1)$ \\
\hline Unknown & $289(8)$ & $391(9)$ & $503(11)$ & $617(12)$ & $592(12)$ & $254(8)$ \\
\hline \multicolumn{7}{|l|}{ Disposition from emergency centre, $n(\%)$} \\
\hline Discharged home & $2051(54)$ & $2230(52)$ & $2400(51)$ & $2460(49)$ & $2504(50)$ & $1489(45)$ \\
\hline Referred to inpatient disciplines & $1270(33)$ & $1372(32)$ & $1444(31)$ & $1477(29)$ & $1610(32)$ & $1298(40)$ \\
\hline Absconded/refused hospital treatment & $229(6)$ & $304(7)$ & $482(10)$ & $651(13)$ & $556(11)$ & $196(6)$ \\
\hline Transferred to higher-level facilities & $17(4)$ & $252(6)$ & $282(6)$ & $263(5)$ & $204(4)$ & $165(5)$ \\
\hline Referred to other facilities & $82(2)$ & $125(3)$ & $75(2)$ & $128(3)$ & $93(2)$ & $78(2)$ \\
\hline Died in emergency centre & $23(<1)$ & $33(<1)$ & $22(<1)$ & $42(1)$ & $47(1)$ & $57(2)$ \\
\hline \multicolumn{7}{|l|}{$\begin{array}{l}\text { Process times (minutes), median } \\
\text { (Q1 - Q3) (maximum) }\end{array}$} \\
\hline To triage $(n=25355)$ & $\begin{array}{l}25(8-63) \\
(1102)\end{array}$ & $\begin{array}{l}32(9-75) \\
(1445)\end{array}$ & $\begin{array}{l}29(10-64) \\
(1504)\end{array}$ & $\begin{array}{l}32(12-68) \\
(1053)\end{array}$ & $\begin{array}{l}21(7-51) \\
(1239)\end{array}$ & $\begin{array}{l}16(5-38) \\
(549)\end{array}$ \\
\hline To consultatio $n(n=25086)$ & $\begin{array}{l}113(55-205) \\
(1551)\end{array}$ & $\begin{array}{l}143(71-275) \\
(4045)\end{array}$ & $\begin{array}{l}198(86-395) \\
(1755)\end{array}$ & $\begin{array}{l}235(105-480) \\
(1552)\end{array}$ & $\begin{array}{l}200(93-369) \\
(2095)\end{array}$ & $\begin{array}{l}88(41-185) \\
(1975)\end{array}$ \\
\hline To disposition decision $(n=25086)$ & $\begin{array}{l}233(135-383) \\
(2880)\end{array}$ & $\begin{array}{l}293(158-503) \\
(6629)\end{array}$ & $\begin{array}{l}361(191-626) \\
(2986)\end{array}$ & $\begin{array}{l}404(208-761) \\
(3409)\end{array}$ & $\begin{array}{l}382(221-602) \\
(5732)\end{array}$ & $\begin{array}{l}270(142-462) \\
(3720)\end{array}$ \\
\hline In emergency centre ( $n=25086)$ & $\begin{array}{l}348(195-618) \\
(7158)\end{array}$ & $\begin{array}{l}430(225-756) \\
(9948)\end{array}$ & $\begin{array}{l}588(297-922) \\
(4919)\end{array}$ & $\begin{array}{l}590(295-1008) \\
(5833)\end{array}$ & $\begin{array}{l}505(296-792) \\
(5733)\end{array}$ & $\begin{array}{l}401(221-656) \\
(3926)\end{array}$ \\
\hline
\end{tabular}




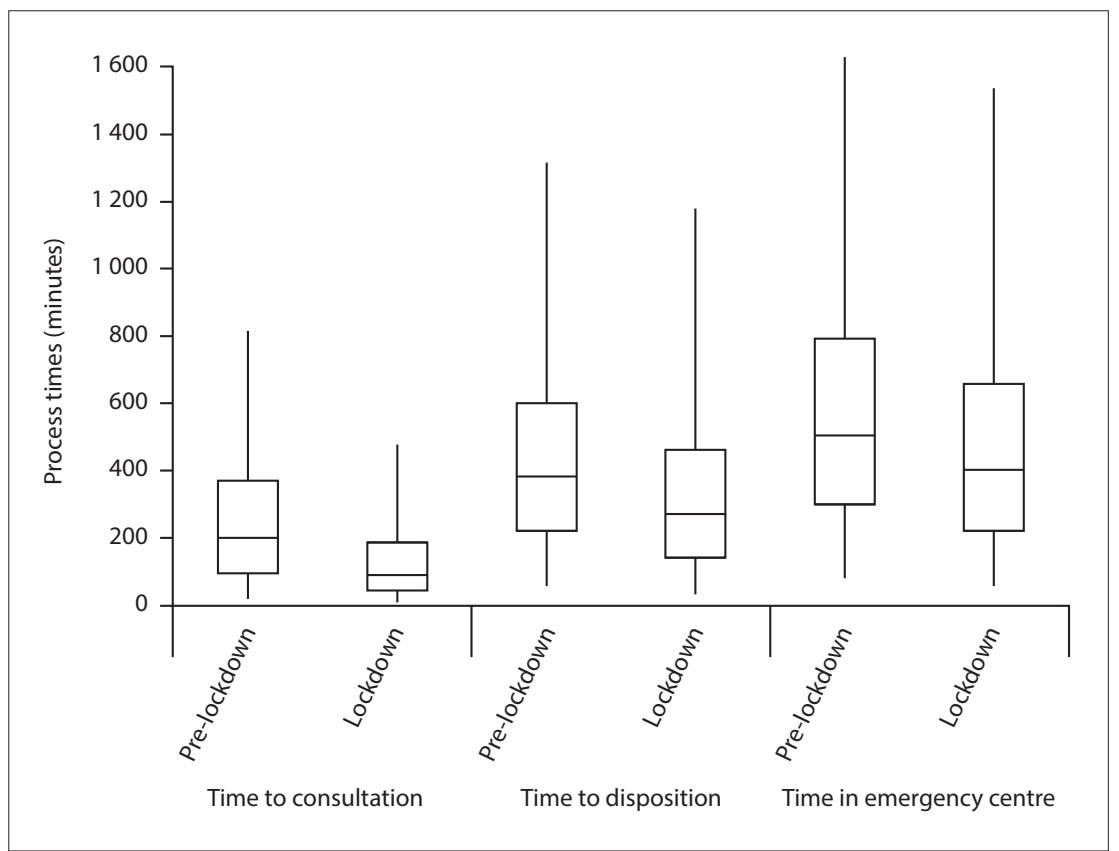

Fig. 4. Process times of patients presenting to the emergency centre for the year 2020 over the 5-week national COVID-19 lockdown period and a similar time period immediately before the lockdown (whiskers represent 2.5 th and 97.5 th percentiles, box represents 25 th, 50 th and 75 th percentiles).

number of patients presenting to the emergency centre. Decreased numbers of emergency visits were witnessed throughout the lockdown period. It is yet to be seen how quickly emergency centre volumes will recover as lockdown measures are eased.

\section{Declaration. None.}

\section{Acknowledgements. None}

Author contributions. DJvH and $\mathrm{CH}$ conceived the study. $\mathrm{CH}$ and $\mathrm{MP}$ undertook data collection and DJvH data management and analysis. DJvH drafted the article and $\mathrm{CH}$ and MP critiqued the paper for important intellectual content. DJvH is the guarantor. Funding. The study was self-funded.

\section{Conflicts of interest. None.}

1. Merriam-Webster. Social distancing. Merriam-Webster.com Dictionary. https://www.merriam-webster.com/dictionary/ social-distancing (accessed 2 June 2020).
2. Centers for Disease Control and Prevention. Social distancing, cdc.gov/coronavirus/2019-ncov/prevent-getting-sick/socialdistancing.html (accessed 2 June 2020).

3. Langton K. Lockdown: Which countries are in lockdown? How many people? Express.co.uk, 26 May 2020. https://www.express. co.uk/news/world/1260709/lockdown-which-countries-arein-lockdown-how-many-people-coronavirus-cases (accessed 1 June 2020).

4. Parpia AS, Ndeffo-Mbah ML, Wenzel NS, Galvani AP. Effects of Parpia AS, Ndeffo-Mbah ML, Wenzel NS, Galvani AP. Effects of
response to 2014 - 2015 Ebola outbreak on deaths from malaria, response to 2014 - 2015 Ebola outbreak on deaths from malaria,
HIV/AIDS, and tuberculosis, West Africa. Emerg Infect Dis 2016:22(3):433-441. https://doi.org/10.3201/eid2203.150977 Rubinson L, Mutter R, Viboud C, et al. Impact of the fall
2009 influenza A(H1N1)pdm09 pandemic on US hospitals. 2009 influenza $\mathrm{A}(\mathrm{H} 1 \mathrm{N1}) \mathrm{pdm} 09$ pandemic on US hospitals.
Med Care 2013;51(3):259-265. https://doi.org/10.1097/ MLR.0b013e31827da8ea

6. Lee SY, Khang YH, Lim HK. Impact of the 2015 Middle East respiratory syndrome outbreak on emergency care utilization and mortality in South Korea. Yonsei Med J 2019;60(8):796-803. https://doi.org/10.3349/ymj.2019.60.8.796

7. Huang H-H, Yen DH-T, Kao W-F, Wang L-M, Huang C-I, Lee C-H. Declining emergency department visits and costs during the severe acute respiratory syndrome (SARS) outbreak S0929-6646(09)60106-6

8. Kaufmann B. Docs fear health impacts of fall in emergency Kaufmann B. Docs fear health impacts of fall in emergency
visits during pandemic. Calgary Herald, 15 May 2020. https:// visits during pandemic. Calgary Herald, 15 May 2020 . https://
calgaryherald.com/news/docs-fear-health-impacts-of-41-fallcalgaryherald.com/news/docs-fear-health-impacts-of-41-fall
in-emergency-visits-during-pandemic (accessed 1 June 2020). in-emergency-visits-during-pandemic (accessed 1 June 2020).
Baldas T. ER visits plummet in pandemic: 'We know more 9. Baldas T. ER visits plummet in pandemic: 'We know more
people are dying at home.' Detroit Free Press, 5 May 2020. https://www.freep.com/story/news/local/michigan/2020/05/05/ keep a safe distance and slow the spread. 2020. https://www

2016;22(3):433-441. https://doi.org/10.3201/eid2203.150977
5. Rubinson L, Mutter R, Viboud C, et al. Impact of the fall during the sections er-visits-plummet-amid-pandemic-we-know-more-peopledying-home/3067993001/ (accessed 1 June 2020).

10. SAnews (South African Government News Agency). President Ramaphosa announces a nationwide lockdown. 23 March 2020. https://www.sanews.gov.za/south-africa/president-ramaphosaannounces-nationwide-lockdown (accessed 2 June 2020).

11. South African Government. President Cyril Ramaphosa: Extension of Coronavirus COVID-19 lockdown to the end of April. 9 April 2020. https://www.gov.za/speeches/presidentcyril-ramaphosa-extension-coronavirus-covid-19-lockdownend-april-9-apr-2020-0000 (accessed 2 June 2020).

12. Bateman C. Critical to protect our doctors and nurses during COVID-19. EthiQal, 28 April 2020. https://ethiqal. co.za/2020/04/28/critical-to-protect-our-doctors-and-nursesduring-covid-19/ (accessed 5 June 2020).

13. Cullinan K. Health services in South Africa: A basic introduction. Health-E News, 29 January 2006. https://www. health-e.org.za/2006/01/29/health-services-in-south-africa-abasic-introduction/ (accessed 19 September 2020).

14. Statistics South Africa. Mitchells Plain. http://www.statssa.gov. za/?page_id=4286\&id=329 (accessed 17 April 2020).

15. Statistics South Africa. Philippi. http://www.statssa.gov, za/?page_id=4286\&id=323 (accessed 17 April 2020).

16. Department: Provincial and Local Government, Republic of South Africa. Mitchell's Plain nodal economic development profile Western Cape. https://mitchellsplain.files.wordpress. com/2011/07/mitchells_20plain_20narrative.pdf (accessed 19 September 2020).

17. South African Triage Group. The South African Triage Scale (SATS). 2012. https://emssa.org.za/special-interest-groups/ the-south-african-triage-scale-sats/ (accessed 28 August 2019).

18. Lu TH, Chou YJ, Liou CS. Impact of SARS on healthcare utilization by disease categories: Implications for delivery of healthare services. Health Policy (New York) 2007:83(2of healthcare services. Health Policy (New York) 2007;83

19. Man CY, Yeung RS, Chung JY, Cameron PA. Impact of 19. Man CY, Yeung RS, Chung JY, Cameron PA. Impact of
SARS on an emergency department in Hong Kong. Emerg Med 2003;15(5-6):418-422. https://doi.org/10.1046/j.14422026.2003.00495.x

20. Chang HJ, Huang N, Lee CH, Hsu YJ, Hsieh CJ, Chou YJ. The impact of the SARS epidemic on the utilization of medical services: SARS and the fear of SARS. Am I Public Health 2004;94(4):562-564. https://doi.org/10.2105/AJPH.94.4.562

21. American College of Emergency Physicians. New poll: Nearly a thich a third are delaying or avoiding medical care due to COVID-19 concerns. 28 April 2020. https://www.emergencyphysicians. org/press-releases/2020/4-28-20-new-poll-nearly-a-third-aredelaying-or-avoiding-medical-care-due-to-covid-19-concerns (accessed 1 June 2020)

22. Payne S. Lockdown saves lives, on the empty roads. Daily Maverick, 17 April 2020. https://www.dailymaverick.co.za/ article/2020-04-17-lockdown-saves-lives-on-the-emptyroads/ (accessed 1 June 2020).

23. National Department of Health, South Africa. Latest confirmed cases of COVID-19 (27th March 2020). SA Corona Virus Online Portal. https://sacoronavirus.co.za/2020/03/27/ latest-confirmed-cases-of-covid-19-27th-march-2020/ (accessed 8 June 2020).

24. Snowdon W. Avoiding emergency care during pandemic a dangerous trend, Edmonton ER doctor warns. CBC News, 15 May 2020. https://www.cbc.ca/news/canada/edmonton/covidcoronavirus-emergency-rooms-1.5571469 (accessed 1 June 2020).

25. Beltrán Guzmán I, Gil Cuesta J, Trelles M, et al. Delays in arrival and treatment in emergency departments: Women, children and non-trauma consultations the most at risk in children and non-trauma consultations the most at risk in
humanitarian settings. PLoS ONE 2019;14(3):e0213362. https://doi.org/10.1371/journal.pone.0213362

Accepted 6 September 2020 